\title{
Daya Angkat dan Tarik Kapal Barang Menggunakan Turbosail Dengan Model Simulasi K-Omega Two Scale
}

\author{
Eka Sari Wijianti, Irfan Wahyudi, Yudi Setiawan \\ Jurusan Teknik Mesin, Universitas Bangka Belitung \\ Jl.Merdeka no. 04 Pangkalpinang \\ E-mail : Eka_ubb@yahoo.co.id
}

\begin{abstract}
Abstrak
Seiring dengan ramainya arus keluar masuk penduduk dan pengiriman barang pribadi melalui paket-paket jasa pengiriman menambah ramainya arus transportasi darat dan laut. Namun, kondisi tersebut tidak dibarengi dengan pengelolaan sumber energi bahan bakar khususnya transportasi laut. Aerodinamis kapal laut harus didukung oleh kecepatan angin yang bertiup di sekitar kapal tersebut. Dengan mendesain sebuah turbosail pada kapal barang, kita dapat mengkolaborasikan sumber energi fosil dan energi angin. Desain Turbosail yang tepat untuk digunakan pada kapal barang.penelitian ini bertujuan untuk mengetahui bagaimana aliran turbulen di sekitar turbosail serta mendapatkan simulasi terbaik. Profil turbovoile dirancang dengan bentuk bulat telur untuk meningkatkan kinerja aerodinamis dengan mengurangi hambatan dengan mengamati koefisien lift dan drag yang dihasilkan dengan Model Simulasi K-Omega Two Scale. Dari hasil penelitian menunjukan bahwa nilai koefisien angkat dan tarik meningkat sesuai dengan kenaikan bilangan Reynolds.
\end{abstract}

Kata kunci : Daya Angkat dan Tarik, Turbosail, K-Omega Two Scale.

\section{Pendahuluan}

Di wilayah eropa, dewasa ini telah banyak model-model kapal yang menggunakan propulsi angin guna mereduksi penggunaan bahan bakar fosil dengan ramainya arus keluar masuk penduduk dan pengiriman barang pribadi melalui paket-paket jasa pengiriman menambah ramainya arus transportasi darat dan laut. Namun, kondisi tersebut tidak dibarengi dengan pengelolaan sumber energi bahan bakar khususnya transportasi laut. Hingga saat ini, kapal laut masih menggunakan bahan bakar fosil sebagai sumber energi utama. Fluktuatif harga minyak mentah berimbas pada harga barang yang masuk dan keluar Bangka Belitung menjadi cenderung mahal ${ }^{[1]}$. Untuk itu perlu dioptimalkan sumber lain untuk mengurangi penggunaan bahan bakar fosil pada bahan bakar kapal laut mengingat mahalnya biaya pengiriman barang menggunakan transportasi udara.

Solusi dari permasalahan tersebut salah satunya adalah dengan menggantikan bahan bakar fosil dengan bahan bakar energy terbarukan, kita dapat memanfaatkan kemajuan teknologi seperti mendesain geometri kapal dengan pemanfaatan propulsi angin. Dengan demikian, kita memerlukan sebuah pemikiran bagaimana caranya agar desain kapal tersebut dapat memberikan model aerodinamis yang baik, sehingga kapal dapat berlayar dengan mengandalkan energy angin tersebut. Dengan mendesain sebuah turbosail pada kapal barang, kita dapat mengkolaborasikan sumber energi fosil dan energi angin. Kita dapat menggunakan energy fosil untuk menggerakkan kapal pada start awal, tetapi pada saat kapal telah berlayar dan kecepatan angin semakin bertambah, kita dapat memanfaatkan propulsi angin yang melewati turbosail sebagai pendorong pergerakan kapal, sehingga kita dapat mematikan motor kapal dan hal ini berarti kita mengefisienkan penggunaan bahan bakar fosil.

Berdasarkan hal tersebut, peneliti ingin mendesain sebuah model turbosail pada kapal barang dengan bentuk dan geometri kompleks sehingga mendapatkan daya angkat yang lebih maksimal dan model yang lebih efisien. Dengan menggunakan program simulasi fluida, peneliti akan mensimulasikan system propulsi angin pada turbosail tersebut menggunakan beberapa software Computational Fluid Dynamic (CFD) ${ }^{[2]}$. Simulasi ini menggunakan beberapa angka 
Reynold berdasarkan kecepatan angin yang berubah-ubah dengan variasi model. Desain Turbosail yang tepat untuk digunakan pada kapal barang.penelitian ini bertujuan untuk mengetahui bagaimana aliran turbulen di sekitar turbosail serta mendapatkan simulasi terbaik.

\section{Metode Penelitian}

Pengendalian aliran sekitar silinder Turbosail dipelajari dengan menggunakan Simulasi Besar Eddy [3]. Kita dapat menggunakan model turbulensi ${ }^{[4]}$ :

- DNS (Simulasi Numerik Langsung)

DNS merupakan solusi numerik dari Navier Stoke dan persamaan kontinuitas. Ketika berhadapan dengan aliran turbulen ini mencoba untuk menyelesaikan semua fenomena turbulen di semua skala panjang dan waktu hanya dengan solusi numerik dari persamaan Navier Stoke dan kontinuitas. Untuk simulasi sukses umumnya harus tahu apa skala terkecil panjang, waktu dan kecepatan. Informasi ini sangat penting dalam rangka untuk ruang jaringan dan skala waktu tindakan. Data ini dapat dengan mudah diperoleh dengan menerapkan teori turbulensi Kolmogorov pada program simulasi.

Dalam simulasi ini, kita menggunakan model simulasi LES Smagorinsky model. Penggunaan formulasi k- $\omega$ di bagian dalam dari lapisan batas membuat model yang digunakan secara langsung di sepanjang dinding melalui sublapisan kental.

a. Two Scale Model

- $\mathrm{Y}+$ adalah jarak dari tepi domain komputasi

- Kedua skala Uk dan $U^{*}$ (kecepatan gesekan) merupakan kecepatan sederhana untuk menghitung, tapi mereka membutuhkan energi turbulen di tengah berdekatan jala ke tepi bagian depan mesh.

- Two Scale Model dimodelkan secara default dalam Code Saturne. Ini sering, terutama dalam kasus-kasus dengan perpindahan panas, mengurangi efek cacat tertentu terletak pada permodelan.

Berdasarkan formula pada HK Versteeg \& W. Malalasekera ${ }^{[5]}$ kita dapat menghitung bilangan Reynolds menggunakan rumus:

$$
R e=\frac{\text { Inertia }}{\text { Viskositas fluida }}=\frac{\rho u L}{\mu}
$$

Dimana $\rho$ adalah densitas cairan, $\mu$ adalah viskositas kinematik fluida, L adalah panjang karakteristik, dan $\mathrm{u}$ adalah kecepatan hulu. Karakteristik aliran turbulensi ditandai oleh perilaku, penampilan yang sangat berantakan tak terduga dan adanya skala spasial dan temporal banyak, fenomena disipatif, terutama 3D nonlinear. Mereka muncul ketika sumber energi kinetik adalah gerakan fluida yang teratur dan dapat diprediksi. Sumber energi dalam aliran dapat mengambil beberapa bentuk gradien tekanan dalam aliran pipa, momentum awal tahun arus perbedaan suhu isotermal. Tahap simulasi dapat di jelaskan sebagai berikut :

- Desain model turbosail

Profil turbovoile dirancang dengan bentuk bulat telur dengan menambahkan spoiler di bagian belakang, tujuannya adalah untuk mengetahui mekanisme fisik yang terkait dengan kelahiran turbulensi dan meningkatkan kinerja aerodinamis dengan mengurangi hambatan dengan mengamati koefisien lift dan drag yang dihasilkan.

- Tahap Preprocessor

Tahap ini merupakan tahap persiapan sebelum melancarkan simulasi.

Membangun geometri dan meshing di program Code Saturne

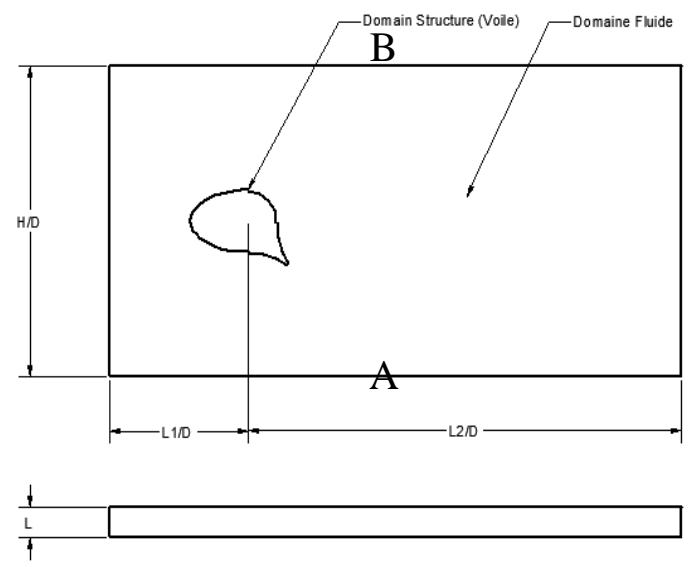

Gambar 1. Kondisi batas model turbosail yang digunakan 
Kondisi batas pada geometri turbosail:

- $\mathrm{AB}$ adalah input

- CD adalah output

- $\mathrm{AC}$ dan BD adalah kondisi simetris

- ABCD untuk kondisi atas dan bawah adalah kondisi simetris

- Layar adalah dinding

Properti fluida (angin) yang digunakan adalah sebagai berikut :

A $\rho$ (densitas) $=1,2 \mathrm{~kg} / \mathrm{m} 3$

A $\mu$ (viskositas dinamik $)=1,8 \mathrm{e}-5$ Pa.s

A $\mathrm{P}($ Tekanan $)=1017,24 \mathrm{~Pa}$

$\mathrm{L}($ Ketebalan mesh $)=1,5 \mathrm{~m}$

Pada penelitian ini Bilangan Reynold untuk tiap kecepatan angin sebagai berikut:

Table 1 Kecepatan dan bilangan Reynold

\begin{tabular}{|c|c|c|c|}
\hline Reynolds & 1000 & 10000 & 100000 \\
\hline $\begin{array}{c}\text { Kecepatan } \\
(\mathrm{m} / \mathrm{s})\end{array}$ & 0.01 & 0.1 & 1 \\
\hline
\end{tabular}

Membuat syntak program numeric (fortran) yang akan digunakan pada program code-saturne berdasarkan formula volume finis dan parameter hasil simulasi seperti Koefisien Angkat $\left(C_{L}\right)$ dan Koefisien tarik $\left(C_{D}\right)$ serta menggunakan beberapa formula volume finis sesuai dengan model simulasi yang digunakan. Kemudian menghitung $\mathrm{CD}$ dan $\mathrm{CL}$ pada file fusproj.f menggunakan rumus berikut ${ }^{[4]}$ :

$$
C_{L}=\frac{F_{y}}{1 / 2 \rho v^{2} S} \quad ; \quad C_{D}=\frac{F_{x}}{1 / 2 \rho v^{2} S}
$$

Dimana $S$ adalah permukaan referen berdasarkan hambatan yang dilalui fluida, $\rho$ adalah masa jenis fluida dan $v$ adalah kecepatan terjauh dari hambatan. Dalam penelitian ini, dimeter turbosail yang kita gunakan, kita ambil diameternya $2 \mathrm{~m}$. Dalam simulasi ini kita menggunakan domain simulasi dengan ukuran koordinat [-12.5;30] x [12.5;30]. Persamaan Navier Stoke diselesaikan untuk kondisi batas berikut:

- Untuk Re 1000, kecepatan $=0,01 / \mathrm{s}$

- Untuk Re 10.000 , kecepatan $0,1 \mathrm{~m} / \mathrm{s}$

- Untuk Re 100.000, kecepatan $1 \mathrm{~m} / \mathrm{s}$
Kondisi batas kecepatan tersebut diterapkan pada panjang domain $\mathrm{x}=30 \mathrm{~m}$ dengan arah horizontal. Eksekusi komputasi dilakukan dengan prosesor ganda dan membutuhkan waktu sekitar 350jam untuk masing-masing model.

\section{HASIL DAN PEMBAHASAN}

\section{Hasil untuk Bilangan Reynold 1000}

Dari hasil simulasi kita mendapatkan streaming line dari medan kecepatan pada gambar 2 yang menunjukkan hasil untuk bilangan Reynold 1000.

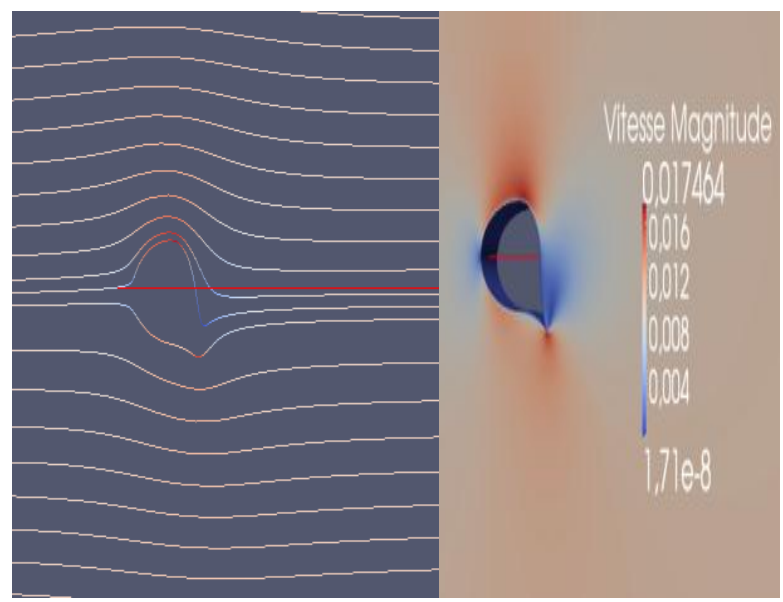

Gambar 2. Stream line untuk Bilangan Reynold 1000

Hasil ini menunjukkan nilai Reynold terendah pada simulasi ini. Berdasarkan hasil tersebut kitabisa melihat arah aliran menunjukkan bahwa turbulen tidak terbentuk di belakang turbosail. Aliran tetap stabil dari pertama memasuki domain (input) kemudian melewati bagian elips dan terakhir melewati ekor terus hingga ke output. Artinya aliran terlihat seperti aliran stabil atau laminar. Medan kecepatan maksimum pada saat aliran melewati turbosail adalah $0,016 \mathrm{~m} / \mathrm{s}$. Koefisien angkat yang dihasilkan tidak menunjukkan hasil yang baik untuk kecepatan $0,01 \mathrm{~m} / \mathrm{s}$, pergerakan grafik menunjukkan penurunan hingga waktu ke 300 detik. Disisi lain, nilai koefisien tarik lebih besar dari koefisien angkat. Artinya, untuk kecepatan $0,01 \mathrm{~m} / \mathrm{s}$, simulasi tidak menunjukkan hasil yang baik, meskipun nilai $C_{L}$ dan $C_{D}$ meningkat. Jadi kita dapat mempertimbangkan bahwa hasil untuk simulasi Re 1000 tidak dapat digunakan sebagai referensi. 


\section{Hasil untuk Bilangan Reynold 10.000}

Sekarang kita akan melanjutkan simulasi untuk Bilangan Reynolds adalah 10.000. Kita akan menampilkan hasil-hasil stream line dari medan kecepatan dalam gambar 3 .

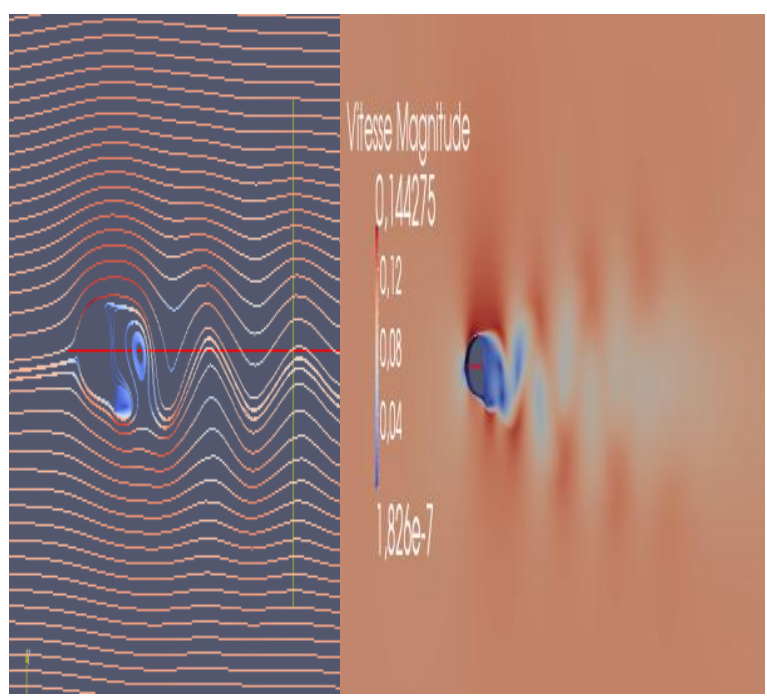

Gambar 3. Medan Kecepatan untuk Bilangan Reynold 10.000

Kita dapat melihat kondisi aliran sangat jelas dan melihat perbedaan tekanan tiap titik berdasarkan nilai dari medan kecepatan. Berdasarkan gambar kita dapat melihat bahwa untuk koefisien tarik kurva menunjukkan kenaikan selama 2,5 detik dan kemudian menurun dan berfluktuasi hingga mencapai nilai stabil. Disisi lain, kurva dari koefisien tarik menunjukkan penurunan dari pertama iterasi dan menjadi stabil pada detik ke-20. Pada model ini, besarnya nilai koefisien tarik dan angkat cenderung berfluktuasi dengan stabil hingga mencapai kondisi konvergen. Namun nilai hasil koefisien angkat lebih kecil dari model simulasi $\mathrm{k}-\omega$, sedangkan untuk koefisien tarik nilainya cenderung lebih besar.

\section{Hasil untuk Bilangan Reynold 100.000}

Sekarang kita akan mengobservasi hasil dari simulasi untuk bilangan Reynolds yang besar yaitu 100.000. Pada saat vortex terbentuk, aliran dissimetrik terbentuk disekitar turbosail, hal ini menyebabkan terjadi perbedaan distribusi tekanan. Ini menunjukkan bahwa perbedaan tekanan dari vortex ini akan menciptakan daya angkat di sekitar turbosail.

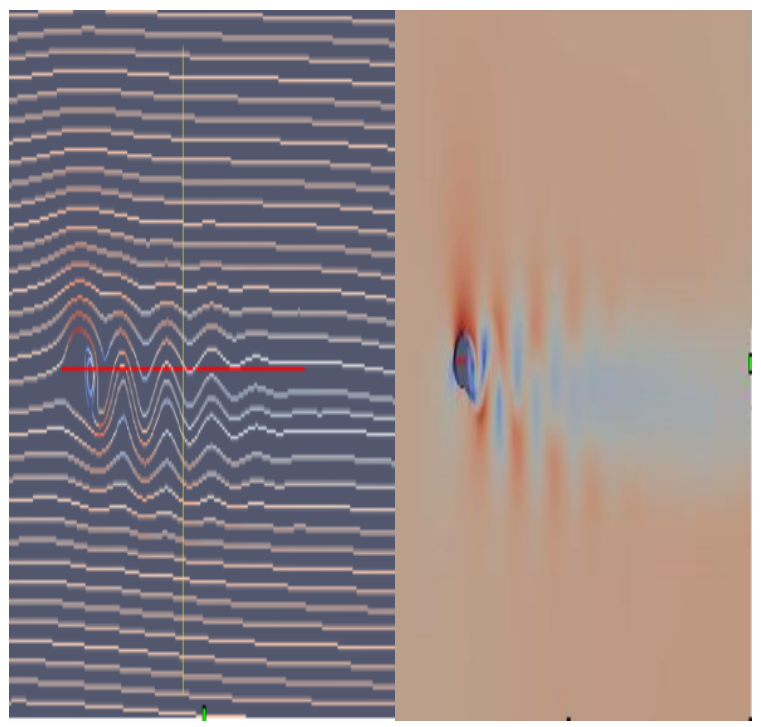

Gambar 4. Medan Kecepatan untuk Bilangan Reynold 10.000

Medan aliran (Stream line) dari simulasi ini menunjukkan hasil yang lebih mirip dengan hasil simulasi dari bilangan Reynolds 10.000. Untuk model k- $\omega$, vortex terbentuk di belakang turbosail selama beberapa detik dan kemudian menjadi stabil hingga menuju output. Disisi lain, kita dapat melihat hasil untuk medan vortex. Untuk model $\mathrm{k}-\omega$, vortex terbesar terbentuk tepat di belakang turbosail. Koefisien tarik menunjukkan delta $C_{L}$ dan $C_{D}$ sejak iterasi pertama, khususnya untuk $C_{D}$, fluktuasi dari nilai tiap point iterasi menunjukkan delta yang besar, yaitu 0,2 .

\section{Perbandingan Nilai Koefisien Angkat dan Koefisien Tarik}

\section{$\mathrm{C}_{\mathrm{L}}$ dan $\mathrm{C}_{\mathrm{D}}$ Maximum}

Setelah mengobservasi hasil dari simulasi untuk beberapa bilangan reynolds, kita akan membandingkan nilai dari koefisien angkat dan tarik maksimum untuk tiap model simulasi yang digunakan. Untuk model k- $\omega$ menunjukkan nilai rata-rata dan cenderung meningkat berdasarkan kenaikan bilangan Reynolds.

\section{Kesimpulan}

Simulasi aliran di sekitar silinder turbosail tanpa kontrol telah dipelajari. Hasil simulasi model k- $\omega$ Two Scale Model untuk RE $10^{3}, 10^{4}, 10^{5}$. Desain ekor dari model turbosail dapat meningkatkan 
koefisien angkat (CL) dan mereduksi koefisien tarik $\left(\mathrm{C}_{\mathrm{D}}\right)$. Perbandingan antara koefisien tarik dan koefisien angkat memberikan hasil yang bervariasi. Nilai koefisien angkat dan tarik meningkat sesuai dengan kenaikan bilangan Reynolds. Jadi, penempatan nilai $\mathrm{y}^{+}$memberikan pengaruh yang sangat $d=$ signifikan .

\section{DAFTAR PUSTAKA}

1. Ekspor- dan Impor /brseximr 06012012. html http: /babel. bps.go.id/ index.php / 20120601718/ [diakses pada tanggal 22 Oktober 2012]

2. DELTEIL Pauline, 2011, Validation $d u$ Code de Calcul CFD Code_Saturne et Application A Plusieurs Cas d'Etude Industriels, Thesis, Université de La Rochelle.

3. Christophe Bailly \& Geneviève ComteBellot (2003), Turbulence, Collection Sciences et Techniques de l'ingénieur, Paris.

4. Power Generation and Environment Department Single Phase ThermalHydraulics Group (EDF R\&D) (2011), Code_Saturne version 2.1.1 Practical User's Guide et Code_Saturne 2.1.1 Theory and Programmer's Guide, Fluid Dynamics.

5. HK Versteeg \& W. Malalasekera (1995), An Introduction to Computational Fluid Dynamic the Finite Volume method, Longman Scientific \& Technical, England. 